\title{
WANDLEXIKON „100 JAHRE TIROLER LITERATUR“
}

\section{von Christian Kössler}

Das im Februar $202 \theta$ installierte tirolensische Kunstwerk im Neubau der Hauptbibliothek zeigt unter dem Motto „100 Jahre Tiroler Literatur" die Namen von 750 Autorinnen und Autoren aus Nord-, Ost- und Südtirol auf 40 Metern Länge und macht so das umfangreiche literarische Schaffen im Land sichtbar. Inhaltlich wurde dabei keine Wertung vorgenommen - BestsellerautorInnen stehen neben literarischen Mauerblümchen.

\section{Enge universitäre Kooperation}

Das Projekt wurde in Kooperation mit dem Forschungsinstitut Brenner-Archiv der Universität Innsbruck umgesetzt. Als inhaltliche Grundlage diente das Literatur-Lexikon des Archivs auf "literaturtirol.at".

Vizerektorin Ulrike Tanzer betonte bei der offiziellen Einweihungsfeier im Historischen Lesesaal der Universitäts- und Landesbibliothek die hervorragende Kooperation zwischen Bibliothek und Archiv.

In einem weiteren Schritt werden nun die urheberrechtsfrei zugänglichen Werke der abgebildeten Schriftstellenden digitalisiert. Diese sind dann im Volltext über die Digitale Bibliothek der Universitäts- und Landesbibliothek Tirol https://diglib.uibk.ac.at/ zugänglich sowie im Literaturlexikon verlinkt.

\section{Landesbibliothek und literarisches Gedächtnis}

Sämtliche in und über Tirol publizierten Medien (Bücher, Zeitschriften, Zeitungen usw.) werden in gedruckter oder elektronischer Form gesammelt und archiviert, sind aber öffentlich und kostenlos zugänglich. Die Sammlung erstreckt sich auch auf historisches Schrifttum und seinen Erhalt. Wertvolle regionale Altbestände werden digitalisiert und im urheberrechtlich zulässigen Umfang öffentlich zugänglich gemacht.

Durch die Sammlung thematisch mit Tirol befasster Regionalliteratur, wird die die Entwicklung der Region in Geschichte und Gegenwart dokumentiert und damit Forschung, Arbeit und Bildung in der Region unterstützt. 
Das Projekt wurde von der Transferstelle Wissenschaft - Wirtschaft - Gesellschaft der Universität Innsbruck sowie der Stiftung Südtiroler Sparkasse unterstützt.

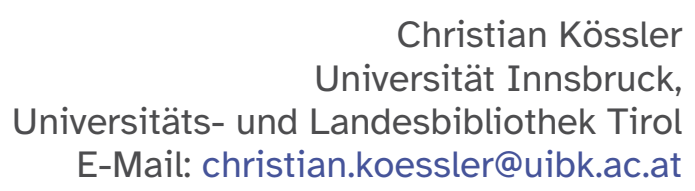

\section{Literatur}

Digitale Bibliothek der Universitäts- und Landesbibliothek Tirol: https://diglib.uibk.ac.at/

Literatur Tirol: https://literaturtirol.at/

Stiftung Südtiroler Sparkasse: https://www.stiftungsparkasse.it/

Universität Innsbruck, Forschungsinstitut Brenner-Archiv: https://www. uibk.ac.at/brenner-archiv/index.html.de

Universität Innsbruck, Transferstelle Wissenschaft - Wirtschaft - Gesellschaft: https://www.uibk.ac.at/transferstelle/

DOI: https://doi.org/10.31263/voebm.v74i1.6053

(C) Christian Kössler

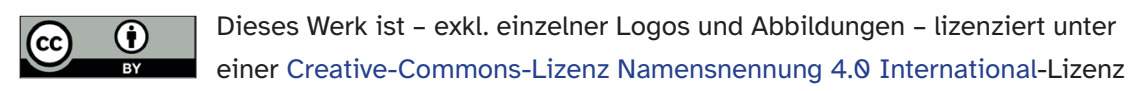

